\title{
De las expectativas a las prácticas. La configuración institucional del poder legislativo mendocino, $1852-1861^{*}$
}

\section{From expectations to practices. The institutional configuration of legislative power in Mendoza. 1852-1861}

\author{
Gabriela García Garino \\ Consejo Nacional de Investigaciones Científicas y Técnicas \\ Instituto Multidisciplinario de Estudios Sociales Contemporáneos \\ Instituto de Estudios Históricos, Económicos, Sociales e Internacionales
}

(Argentina)

gabigarino@yahoo.com.ar

\section{Resumen}

El objetivo del trabajo es analizar la conformación de la sala de representantes de la provincia de Mendoza entre 1852 y 1861 desde una perspectiva institucional que inserte el proceso en la dinámica relacional con los poderes ejecutivo y judicial, también en conformación. Para ello se examinarán los discursos sobre la legislatura en la normativa y en la prensa, pasando luego al estudio cuantitativo y cualitativo de la actuación de la sala. La hipótesis que guía el trabajo sostiene que expectativas altas sobre las posibilidades de la cámara llevaron a la producción de discursos negativos sobre ella, pero el accionar real de los legisladores no habría reflejado tales imágenes.

\footnotetext{
* Una versión preliminar de este trabajo fue presentada en las XIV Jornadas Interescuelas/Departamentos de Historia, realizadas en la Facultad de Filosofía y Letras, Universidad Nacional de Cuyo, Mendoza, del 2 al 5 de octubre del 2013. Agradezco los comentarios de Flavia Macías, Alejandro Eujanián, Fabio Wasserman y Ana Laura Lanteri, las lecturas de Eugenia Molina y las sugerencias de los revisores.
} 
Palabras clave: Legislatura - Instituciones - Estado - Mendoza

\begin{abstract}
The aim of this paper is to analyze the formation of the House of Deputes of the Province of Mendoza between 1852 and 1861. An institutional perspective is chosen to insert the process in the relational dynamic between the executive and judicial powers, also in conformation. In order to accomplish it, the discourses on the Legislature, both in the legislation and in the press, will be examined; going in a second time to the quantitative and qualitative study of the work of the Chamber. The hypothesis that guides the paper argues that high expectations about the possibilities of the House led to the production of negative statements about it. However the actions of legislators would have not reflected such images.
\end{abstract}

Key Words: Legislature - Institution - State - Mendoza

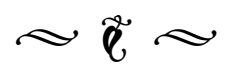

\section{Introducción}

En Mendoza, la década de 1850 -fijando sus límites entre la caída de Rosas y la llegada de Sarmiento como enviado de Mitre tras la batalla de Pavón en enero de 1862-, se caracterizó por cierta conflictividad debida a la configuración de la Confederación, la (re) incorporación de los emigrados políticos y el diseño institucional. En ese contexto, se realizará un análisis del rol asignado a la sala en la normativa y en la prensa, como de su praxis institucional, mostrando cuál fue su producción, qué temas abarcó y cómo fue estructurando su rol y protagonismo a través de las relaciones con los otros dos poderes. El trabajo se limitará a la dimensión institucional del desarrollo de la legislatura, dejando para otros estudios los aspectos más vinculados a las disputas políticas. Así, se tratará de insertar su actuación en la dinámica relacional con los otros dos poderes -ejecutivo y judicialconsiderando que estos también estaban en construcción. ${ }^{1} \mathrm{El}$ recorte del objeto de estudio responde al lugar que tuvieron estos organismos en las ingenierías institucionales de la segunda mitad del siglo XIX, ya que allí se designaba al gobernador y a los senadores para el Congreso, examinando la validez de los comicios. $^{2}$

1.El trabajo se inserta en una investigación mayor sobre la cultura política durante la configuración del estado provincial entre 1852-1881.

2. SABATO, Hilda, Historia de la Argentina, 18521890, Siglo XXI, Buenos Aires, 2012; PAZ, Gustavo, “El gobierno de los 'conspicuos': familia y poder en Jujuy, 1853-1875” y BRAVO, María Celia, "La política "armada" en el norte argentino. $\mathrm{El}$ proceso de renovación de la elite tucumana (1852-1862)", en SABATO, Hilda y LETTIERI, Alberto (compiladores) La vida politica del siglo XIX. Armas, votos y voces, Fondo de Cultura Económica, Buenos Aires, 2003, pp. 223-234 y pp. 243-258 respectivamente; NAVAJAS, María José, Actores, representaciones, discursos y prácticas. La politica en Tucumán, Argentina, 1852-1887, tesis doctoral inédita, El Colegio de México, México, 2008, pp. 33-86 y BUCHBINDER, Pablo, Caudillos de pluma y hombres de acción. Estado y política en Corrientes en tiempos de la organización nacional, Prometeo/Universidad Nacional de General Sarmiento, Buenos Aires, 2004, pp. 49-71. 
Bransboin $^{3}$ ha estudiado la construcción y ejercicio del poder de legislatura y gobernadores en el período 1831-1852, señalando que el consenso existente entre las élites habría abierto espacios para la sala, otorgándole un rol político clave. Por su parte, Seghesso y Pérez Guilhou ${ }^{4}$ han indicado que si bien la cámara ocupó la primacía en el diseño constitucional, en realidad tuvo una presencia débil, pues habría sido el ejecutivo quien tomó la iniciativa. Según la hipótesis de este trabajo ambos autores habrían reproducido en cierta medida las representaciones negativas de la prensa de la época, pues habrían sido las elevadas expectativas sobre las posibilidades del poder legislativo para modificar la realidad política las que dieron lugar a imágenes negativas de éste, al menos tal como fueron expresadas por la prensa. En este sentido, un análisis de las prácticas en el interior de la dinámica institucional mostraría una productividad mayor a la señalada por los artículos periodísticos, así como los esfuerzos de la sala por posicionarse como "primer poder". De hecho, es posible que fuera este accionar el que terminara por causar un aumento de la conflictividad con los otros cuerpos del estado provincial hacia finales de la década.

\footnotetext{
3. Agradezco al autor el acceso a su versión original. BRANSBOIN, Hernán, Mendoza Confederal. El ejercicio de la soberanía mendocina en torno a la Confederación Argentina. 1831-1852, tesis doctoral inédita. Facultad de Filosofía y Letras, Universidad Nacional de Buenos Aires, Buenos Aires, 2012.
}

\section{SEGHESSO DE LÓPEZ, Cristina, Historia} constitucional de Mendoza, Instituto Argentino de Estudios Constitucionales y Políticos, Mendoza, 1997, pp. 179-180 y PÉREZ GUILHOU, Dardo, “E1 Ejecutivo Colegiado en la Constitución mendocina de 1854" y "Repercusiones de Pavón en Mendoza (18611879), en PÉREZ GUILHOU, Dardo, Ensayos sobre la historia institucional de Mendoza, Senado de la Nación, Buenos Aires, 1997, pp. 29-54 y 69-93.
Una primera parte está dedicada al diseño institucional de la cámara en la normativa, a una breve reseña del acontecer político del período y a las representaciones de la prensa sobre aquella. En la segunda sección, se presenta un análisis de la actividad de la sala en términos de su productividad, de su accionar en el juego electoral y su vinculación con los poderes judicial y ejecutivo, dando cuenta de los momentos de tensión y consenso.

\section{La estructura de la sala a partir de la nueva constitución provincial}

La sala de representantes ${ }^{5}$ surgió en 1820 con el nombre de "Junta Representativa del Pueblo Soberano". A lo largo del decenio, el organismo se convirtió en el poder legislativo, al delinear sus funciones y aumentar la cantidad de sus miembros, que desde 1824, se eligieron en forma directa. En 1827, se establecieron los requisitos para ser diputados y la renovación de la sala por mitades cada seis meses; al año siguiente se dictó un reglamento interno que seguiría vigente hasta 1862. Allí se pautaba que el presidente dirigía los debates, cuidando el orden y que sólo votaba para desempatar; se fijaban cuatro comisiones permanentes de tres miembros cada una -legislación, hacienda, peticiones y guerra- y se facultaba al gobernador o a tres diputados a convocar sesiones extraordinarias. Debido a las dificultades para reunir quórum, se lo fijó en la mitad de los legisladores. ${ }^{6}$

\footnotetext{
5. En el trabajo se usarán los términos legislatura, sala, cámara de representantes y de diputados de forma separada o en combinaciones como sinónimos, ya que se han hallado tales fórmulas en las fuentes.
}

6. SEGHESSO DE LÓPEZ, Cristina, Historia..., 
En 1854 se dictó la constitución provincial, la que prácticamente no innovó en esta materia: se mantuvieron los requisitos para ser representante (ciudadanía argentina, domicilio en Mendoza, 25 años de edad y una propiedad raíz o renta equivalente a un capital de 4000 pesos) pero se estableció la incompatibilidad de ser empleado asalariado de los ejecutivos provincial y nacional y el ser eclesiástico regular, excluyendo a procesados y discapacitados. Se fijaron dos periodos de sesiones permanentes por año, del 3 de febrero al 30 de abril y del $1^{\circ}$ de agosto al 31 de octubre. Entre sus atribuciones, se establecieron la designación del gobernador y senadores nacionales; el examen de la elección de sus integrantes; el dictado de leyes en lo municipal, civil y judicial; las operaciones con tierras fiscales, tratamiento de pedidos de renuncia y licencia del gobernador, y designación de interinos; fijación del presupuesto, los impuestos y examen de rendiciones de cuentas. Los mayores cambios afectaron al tratamiento de las leyes, exigiendo tres lecturas en sesiones diferentes; además, toda ley debía ser promulgada por el gobernador. También mantenía la inmunidad de los diputados en el ejercicio de sus funciones. ${ }^{7}$

La elección del gobernador por la sala había sido establecida por la ley electoral de

Op. Cit., pp. 174-212; COMADRÁN RUIZ, Jorge,

"Notas sobre la creación y evolución de la legislatura de

Mendoza, 1820-1854", en Revista de Historia Americana y Argentina, Mendoza, 1972-1979, No 17-18, pp. 29-67.

7.AHUMADA, Manuel de, Código de las Leyes, Decretos y Acuerdos que sobre Administración de Justicia se han dictado en la provincia de Mendoza. Mandado formar por el Exmo. Gobierno en su decreto del 16 de enero de 1860, Imprenta de "El Constitucional", Mendoza, 1860, pp. 312-315; SEGHESSO DE LÓPEZ, Cristina, Historia ..., Op. Cit., pp. 174-212.
1827 y según Seghesso subordinaba el poder ejecutivo al legislativo, lo que no sólo era incompatible con la división de poderes, sino que produjo varios conflictos, ya que el primero trataba de digitar la conformación del segundo para controlar la sucesión. ${ }^{8}$ Aun así, el poder ejecutivo fue dotado de amplias atribuciones por la constitución: era agente del gobierno federal para el cumplimiento de la legislación nacional; llamaba a elecciones, tenía facultad para indultar y conmutar penas, celebrar tratados y ejercer el patronato; nombraba a los empleados de la administración; designaba los magistrados y movilizaba las guardias nacionales. Además, tenía funciones colegisladoras, como la promulgación o veto de las leyes, el llamado a sesiones extraordinarias y la presentación anual del presupuesto, leyes de impuestos y rendiciones de cuentas.

Respecto del poder judicial, las innovaciones constitucionales apuntaron a ciertas atribuciones y facultades para hacer efectiva la independencia de la justicia: ${ }^{9}$ la inamovilidad de los jueces y la intangibilidad salarial. ${ }^{10}$

De la descripción se destacan ciertas

8. Ídem, pp. 70-71.

9. Se ha indicado en el período 1831-1852 la presencia de idearios republicanos que concebían la separación de poderes como uno de los elementos más importantes; pero la pervivencia de una cultura política tradicional que identificaba la justicia con la conservación de un orden social inmanente y por lo tanto como atribución del poder político, ayuda a explicar las frecuentes injerencias de los gobernadores en la justicia, que hacían que la independencia de ésta prácticamente desapareciera. BRANSBOIN, Hernán, Mendoza ..., Op. Cit., pp. 114155.

10.AHUMADA, Miguel de, Código..., Op. Cit., pp. 315-317; SEGHESSO DE LÓPEZ, Cristina, Historia..., Op. Cit., pp. 72-126; 239-255. 
particularidades. Por un lado, es notoria la vigencia de un reglamento de debates que había sido establecido en 1828 y que atravesó indemne el período rosista, lo que señala cierta valorización de prácticas precedentes. Por el contrario, la incompatibilidad entre los cargos legislativos y los cargos pagados por el ejecutivo provincial y nacional sí implicó una ruptura respecto del período anterior, buscando la separación de poderes, propia del régimen republicano buscado. ${ }^{11}$ Finalmente, el influjo de Juan Bautista Alberdi -autor de la ley fundamental de Mendoza- se percibe en las amplias atribuciones dadas al poder ejecutivo que indican la necesidad de un poder rápido y ágil. ${ }^{12}$

Entre 1832 y 1852, Bransboin señala que la trayectoria institucional mendocina, a diferencia de otras provincias donde se dio una endémica inestabilidad o la perpetuación de un gobernante, combinó la alternancia en el ejercicio de la gobernación con la estabilidad; de hecho, sólo un mandatario ${ }^{13}$ del período fue derrocado por un alzamiento que contó con el beneplácito de Juan Manuel de Rosas. E1 autor aduce que la estabilidad se debió a rasgos institucionales como la elección del gobernador por una sala doblada, lo que generaba consenso, y a la pertenencia de las dirigencias a los principales sectores productivos, haciendo

11. Ante dudas planteadas por jueces que habían sido electos representantes, se dispuso la compatibilidad entre ambos, lo cual respondía, según Seghesso, a la falta de candidatos aptos para cumplir las funciones gubernamentales. SEGHESSO DE LÓPEZ, Cristina, Historia..., Op. Cit., p. 52. Ver nota 91.

12. Ídem, pp. 219-232.

13.Pedro Pascual Segura depuesto en 1847.BRANSBOIN, Hernán, Mendoza..., Op. Cit.., pp. 70-71. que la legislación protegiera estos intereses. ${ }^{14}$

Como en la mayoría de las provincias de la Confederación, tras la victoria de Urquiza, los elencos locales se adaptaron a la nueva situación. ${ }^{15}$ El gobernador Mallea dimitió el 2 de marzo de 1852, y la legislatura autoconvocada repuso a Segura como gobernador provisorio, derogando después las facultades omnímodas dadas a Rosas. Esta etapa se caracterizó por la (re)incorporación de los exiliados que regresaban y los conflictos desatados entre poderes, devenidos algunos del sistema institucional ${ }^{16}$ y otros de la dinámica local y regional. En este sentido, el enfrentamiento entre la Confederación y el estado de Buenos Aires y los brotes de violencia en San Juan nutrieron las tensiones internas de Mendoza. Las dirigencias de éstas en general apoyaron al gobierno de Paraná aunque el consenso se empezaría a resquebrajar hacia 1860, cuando las tensiones internas de la Confederación se incrementaran.

De esta manera, los gobiernos de Segura (1852-856), Moyano (1856-1859) ${ }^{17}$ y Nazar (1859-1861), ${ }^{18}$ enfrentaron oposición de la

14. Ibídem.

15. SABATO, Hilda, Historia..., Op. Cit..

16. SEGHESSO DE LÓPEZ, Cristina, Historia ..., Op. Cit., pp. 174-180.

17.A finales de su mandato (febrero de 1859) se produjo un grave conflicto con la sala respecto de la duración de su período lo que terminó con el envío de un comisionado nacional. Juan Cornelio Moyano había tenido un entredicho con la cámara de justicia provincial a lo largo de 1858. Ambos casos serán analizados en la última sección del artículo. MARTÍNEZ, Pedro Santos, Mendoza durante la escisión nacional, 1852-1862, C.E.I.H.C., Mendoza, 2007, pp. 75-77; 135-137; 149150.

18. Entre abril y agosto de 1859 , el poder ejecutivo estuvo 
sala, y divisiones dentro de ésta que podrían pensarse como fracciones de las élites. La crisis fiscal dada por el pase de las aduanas provinciales al estado nacional agravó las tensiones en un momento donde se requería de creciente personal para las nuevas instituciones y era necesario invertir en obras, incrementando los gastos. ${ }^{19}$

El gobierno nacional ensayaba la construcción de su esfera estatal con la puesta en marcha de instituciones que centralizaban la organización militar, el sistema fiscal y las comunicaciones. Por su parte, los gobiernos provinciales debían ceder cuotas de poder al estado federal, poniendo fin al ejercicio de una soberanía autónoma durante la primera mitad del siglo. La injerencia del nuevo actor sobre los escenarios provinciales dependió de las condiciones locales, generando respuestas que variaron entre la colaboración, la oposición y el conflicto. De todas formas, el gobierno nacional asentado en Paraná tuvo dificultades para establecer rentas suficientes que sostuvieran las instituciones estatales. ${ }^{20}$ Mientras, el estado de Buenos Aires mostró durante esta década

a cargo del interventor Pascual Echagüe. Laureano Nazar fue designado en agosto; su mandato se vio sacudido por el terremoto de marzo de 1861, que destruyó Mendoza y por los efectos de Pavón, viéndose obligado a renunciar a favor de Juan de Dios Videla en diciembre. Éste no fue aceptado por Sarmiento, que acompañaba al ejército porteño, quien sugirió a una asamblea popular la elección de Luis Molina el 2 de enero de 1862. Tal procedimiento anticonstitucional fue refrendado por la sala en febrero. Ídem, pp. 149-154; 165-168; 201-206.

19. MARTÍNEZ, Pedro Santos, Mendoza ..., Op. Cit.; SCALVINI, Jorge, Historia de Mendoza, Spadoni, Mendoza, 1965.

20.LANTERI, Ana Laura, De lo ideal a lo posible. Dirigencia e instituciones nacionales en la 'Confederación' (1852-1861), tesis doctoral inédita, Universidad Nacional del Centro de la Provincia de Buenos Aires, Tandil, 2011. prosperidad y dinamismo político, asentado en los recursos de su aduana. ${ }^{21}$

\section{Las expectativas de los actores: miradas a través de la prensa}

El principal diario mendocino del período fue El Constitucional (1852-1884),22 cuya edición por la imprenta estatal y subvención recibida por el gobierno ${ }^{23}$ le dieron carácter oficial $^{24}$ y continuidad. Esta última característica lo convierte en una fuente privilegiada, frente a otras publicaciones realizadas por opositores, de las que sólo han llegado números sueltos. La publicación no escapa al carácter de la prensa decimonónica, como productora de "hechos políticos", ${ }^{25}$ funcionando como portavoz y formadora

21.LETTIERI, Alberto, La república de la opinión. Política y opinión pública en Buenos Aires entre 1852 y 1862, Biblos, Buenos Aires, 1998.

22. Ver un análisis de la prensa mendocina en la primera mitad del siglo XIX, en MOLINA, Eugenia, El poder de la opinión pública. Trayectos y avatares de una nueva cultura política en el Río de la Plata, 1800-1852, Universidad Nacional del Litoral, Santa Fe, 2009, pp. 217-251.

23. Para analizar la problemática de la dependencia de los diarios respecto al gobierno o algún grupo político en el estado de Buenos Aires, véase: WASSERMAN, Fabio, "La libertad de imprenta y sus límites: prensa y poder político en el Estado de Buenos Aires durante la década de 1850", en Almanack Braziliense, São Paulo, noviembre 2009, № 10, pp. 130-146. Este tema fue uno de los argumentos de la legislatura en el enfrentamiento que tuvo con el gobernador Nazar en 1860 (ver último apartado).

24. El diario trató de negar su pertenencia al oficialismo en varias ocasiones. El Constitucional (en adelante $E$. C.), Mendoza, 6/5/; E. C., Mendoza, 21/7/1860 (en el subtítulo se aclaraba: "Este diario no es oficial").

25. PALTI, Elías, El tiempo de la política. El siglo XIX reconsiderado, Siglo XXI, Buenos Aires, 2007, p. 192. 
de identidades y grupos políticos. ${ }^{26}$ Así, El Constitucional reflejaba en gran medida la voz del ejecutivo provincial ${ }^{27}$ que le brindaba sostén económico y sus discursos sobre la sala no fueron ajenos a la dinámica que atravesó la relación entre ambos poderes. La publicación también exhibía la opinión favorable al gobierno de la Confederación de los titulares del ejecutivo provincial.

Hubo varios editores y/o redactores. ${ }^{28} \mathrm{El}$ más relevante fue Damián Hudson (18081875), responsable del periódico entre 1854 y 1856, el cual se había exiliado en Chile durante la década de 1840, volviendo en 1850 para ejercer como representante (1854-

26. Numerosos estudios dan cuenta de las características de la prensa decimonónica. Entre ellos: CUCCHI, Laura y NAVAJAS, María José, “Un actor 'incómodo': prensa política en Córdoba y Tucumán a fines de la década de 1870. Discursos, prácticas y representaciones", en Secuencia. Revista de Historia y Ciencias Sociales, México, enero-abril de 2012, No 82, pp. 41-71; BONAUDO, Marta, "De la opinión publicada a la opinión pública. La prensa como lugar de representación y conflicto", en BONAUDO, Marta (coordinadora) Imaginarios y prácticas de un orden burgués. Rosario, 1850-1930: Los actores entre las palabras y las cosas, Prohistoria, Rosario, 2005, pp. 71-95; ALONSO, Paula (compiladora) Construcciones impresas. Panfletos, diarios y revistas en la formación de los estados nacionales en América Latina, 18201920, Fondo de Cultura Económica, Buenos Aires, 2004.

27. En términos estrictos, el diario pertenecía al gobierno provincial, sin embargo, tanto en los discursos como en la práctica contemporánea, éste era identificado con el poder ejecutivo. Ver nota 43.

28. Si bien no siempre se los mencionaba y las colecciones consultadas no están completas, para este período podemos nombrar a Antonio María Fernández (27/6 24/8/1853), la dupla Damián Hudson (9/5- 22/5/1854 como "dueño y redactor", aunque éste ofreció su renuncia recién el 1/2/1856 como redactor) y Augusto Saillard (9/5-22/5/1854 como editor responsable), Justino Méndez (12/1-8/3/1856 y 1/2/1860), Juan Monteros (15/3-24/10-1856), Juan Ramón Muñoz (31/87/12/1857). Se debe indagar en su filiación.
1856), convencional provincial (1854) y juez de letras en lo civil (1859-1860). Fue además funcionario nacional en Paraná y en Buenos Aires, donde llegó a dirigir el Registro Estadístico Nacional. ${ }^{29}$ Su trayectoria pública denota la misma imbricación entre prensa y gobierno. $^{30}$

La legislatura aparecía de dos formas en El Constitucional entre 1852 y 1860. Por un lado, era vista como la clave para organizar la nación y la provincia, al producir las leyes que garantizarían el progreso; por otro, se reprochaba a los legisladores el incumplimiento de su deber. Estas visiones podrían ser encuadradas como el contraste entre el "deber-ser" de la sala y unas prácticas legislativas que no satisfacían las expectativas de ciertos sectores de la élite, y especialmente del poder ejecutivo.

Como ejemplo de la primera perspectiva, un editorial de 1852 convocaba a los legisladores a organizar el país. También expresaba que el accionar de los diputados ya no debía ser pasivo, como lo había sido durante el período previo, sino que debían estar a la altura de las circunstancias. ${ }^{31}$ Durante 1853 , se alentó a la sala a sancionar la constitución provincial. ${ }^{32}$ Pero, además, fue frecuente que el periódico señalara una agenda prioritaria, referida a las

29. GARCÍA GARINO, Gabriela, "Honor y libertad de prensa: dos casos por injuria (Mendoza, 1860)", en Estudios Avanzados, Santiago de Chile, junio 2012, № 17, pp. 63-83.

30. Los redactores de los diarios tucumanos también tenían experiencia política y pública previa, como la participación en clubes y/o cargos estatales. NAVAJAS, María José, Actores..., Op. Cit., p. 59.

31.E. C., Mendoza, 6/5/1852.

32.E. C., Mendoza, 4/8/1853. 
rentas provinciales, la reforma de la justicia, la irrigación, el régimen municipal y la ley de elecciones. ${ }^{33}$ Este tipo de discursos ilustran la fe en el poder de la legislación para cambiar la sociedad, al expresar que "[e]s tiempo ya pues de poner manos a la obra de la regeneracion social, politica i civil de la provincia”. ${ }^{34}$

Por otra parte, el diario oficial hacía las veces de "diario de sesiones", ya que publicaba las actas o resúmenes de éstas. En ocasiones, se podía proseguir con algún debate iniciado en la sala, retomando argumentos y razonamientos presentados en el recinto. ${ }^{35}$ Así, durante 1854 se aludió a la convención constituyente provincial, ya que aquella funcionó entre julio y noviembre de ese año.

Sin embargo, fueron frecuentes las quejas respecto de la no concurrencia de los diputados, que impedía que se sesionara por "falta de número" ${ }^{36}$ o, en el caso de que se reunieran, la pérdida de tiempo en discusiones

33.E. C., Mendoza, 26/2/1856.

34.E. C., Mendoza, 2/4/1856. Las ideas similares están presentes en una nota del poder ejecutivo a la sala de noviembre de 1855 , exp. 1036, carp. 26, y en un discurso del gobernador Moyano al año siguiente, exp. 1068, carp. 27, ambos en el Archivo Legislativo de Mendoza (en adelante ALM). La misma convicción se ve en los proyectos del gobernador Pujol en Corrientes a fin de modernizar el estado modificando el régimen de propiedad, las instituciones políticas y el régimen fiscal a través de la legislación. BUCHBINDER, Pablo, Caudillos..., Op. Cit., pp. 49-71.

35.E. C., Mendoza, 11/8/1854; E. C., Mendoza, 13/5/1854; E. C., Mendoza, 28/6/1855; E. C., Mendoza, 28/12/1855; E. C., Mendoza, 5/3/1856; E. C., Mendoza, 28/4/1856.

36. E. C., Mendoza, 23/8/1853; E. C., Mendoza, 1/6/1855; E. C., Mendoza, 12/1/1856; E. C., Mendoza, 11/8/1856; E. C., Mendoza, 14/11/1857.

26 estériles. ${ }^{37}$ Asimismo, se le reprochaba no sólo su carencia de iniciativa, sino de colaboración hacia el poder ejecutivo, que enviaba proyectos de ley -de municipalidades, ${ }^{38}$ de impuestos, ${ }^{39}$ de presupuesto, ${ }^{40}$ etc.-, que reposaban en las comisiones o en la secretaría. ${ }^{41}$ En 1853 se comparaba a la legislatura con el ejecutivo, aseverando que la primera era una rémora de un pasado arcaico que no acompañaba al ejecutivo en su marcha al progreso. ${ }^{42}$ También se criticaba

37. E. C., Mendoza, 2/6/1855; E. C., Mendoza, 13/2/1856.

38. E. C., Mendoza, 18/1/1856; E. C., Mendoza, 11/11/1856; E. C., Mendoza, 26/2/1857.

39. E. C., Mendoza, 23/2/1856; E. C., Mendoza, 9/3/1857.

40. E. C., Mendoza, 2/4/1856. Estas críticas podían relacionarse con intereses sectoriales. En mayo de 1855, se cuestionó a los legisladores que proponían la reducción de la partida dedicada a imprenta del presupuesto, reduciendo la suscripción para éste y eliminando el periódico oficial 25 de Mayo. E. C., Mendoza, 18/5/1854.

41. E. C., Mendoza, 15/5/1855. Las quejas no eran infundadas, como indican las vicisitudes de la mesa de estadística, creada por decreto del ejecutivo el 19 de septiembre de 1852, tras lo cual envió un proyecto a la sala para su confirmación por ley. La comisión de hacienda se expidió el 21 de febrero de 1853, pero la legislatura rechazaría el proyecto en 1855 y 1857 . Sólo en octubre de ese año, el ejecutivo introdujo un nuevo proyecto que no sería tratado. Ver 11 de agosto de 1857 , exp. 1104, carp. 28, ALM y sesión del 16 de octubre de 1857, ALM, Libro de Actas de la Legislatura, 1854-1859, T. VI.

42. E. C., Mendoza, 10/8/1853. El Constitucional también cuestionaba a funcionarios de los poderes ejecutivo $\mathrm{y}$ judicial, pero se exceptuaba al gobernador, quizás para resguardar su investidura. También puede haber influido la identificación de "gobierno" con "poder ejecutivo". El carácter polémico y crítico de la prensa respondía, por otra parte, a los designios de actuar como "censor" del gobierno y defender los intereses públicos, según la misión que se otorgaba a la prensa decimonónica. Palti habla del modelo "forense" o "jurídico" de la opinión pública, en el cual aquella ofrecía una plataforma de discusión para su conformación y, al mismo tiempo, era 
la legislación, considerando preferibles leyes más sencillas, a fin de que fueran más fáciles de cumplir y no se superpusieran. ${ }^{43}$ Finalmente, el talante crítico del diario alcanzó tal nivel, que dio lugar a conflictos entre ambos poderes. ${ }^{44}$ A veces las críticas de lo que se consideraba como negligencias de la sala ${ }^{45}$ o usurpación de atribuciones correspondientes a otras instancias, procedían de cartas de particulares.

Así, las representaciones de la legislatura en la prensa del período se articularon alrededor de dos ejes. Por un lado, se exaltó la capacidad de la sala para modificar la sociedad mediante la legislación, de transformar y orientar las sociedades al progreso de forma instantánea. Sin embargo, la realidad pronto se impondría, dando lugar a un "desencantamiento" en relación a la legislatura, la cual no legislaba de forma rápida ni perfecta y respecto de normas que tampoco modificaban automáticamente la

su portavoz. Ver PALTI, Elías José, La invención de una legitimidad. Razón y retórica en el pensamiento mexicano del siglo XIX. (Un estudio sobre las formas del discurso político), Fondo de Cultura Económica, Buenos Aires, 2008, pp. 47-287.

43.E. C., Mendoza, 26/2/1857.

44. Este tema será tratado en el último apartado.

45.En 1856 "unos mendocinos" cuestionaron la pasividad de la sala frente a la nota del poder ejecutivo nacional donde informaba de los sucesos del conflicto con Buenos Aires. E. C., Mendoza, 29/3/1856. Un año más tarde, se criticó a los legisladores por una supuesta infracción de la constitución, que hacía incompatible la pertenencia a la sala con el goce de un cargo en el ejecutivo nacional y/o provincial; la respuesta defendiendo el accionar de la cámara provino de otro lector. Ver: $E$. C., Mendoza, 3/12/1857 y E. C., Mendoza, 7/12/1857, respectivamente. Además E. C., Mendoza, 14/2/1856; E. C., Mendoza, 15/2/1856; E. C., Mendoza, 29/3/1856; E. C., Mendoza, 17/11/1857. Si bien las cartas parecían pertenecer a lectores que en general no firmaban con su nombre, quizás fueron escritas por los editores para alimentar el debate. realidad. Por otro lado, no es posible deslindar el rol de El Constitucional como portavoz del ejecutivo de las imágenes que produjo sobre la sala ni de los momentos que atravesó la relación entre ambos poderes que, hacia finales de la década, alcanzaría un elevado grado de conflictividad.

En este sentido, puede resultar interesante añadir al estudio de los discursos sobre la legislatura, un análisis de lo que efectivamente debatió, hizo y legisló la sala a fin de mostrar otro aspecto del proceso de conformación del entramado institucional.

\section{Las prácticas legislativas}

\section{La legislatura en números}

Un análisis cuantitativo de los libros de sesiones conservados hasta 1859, muestra que los legisladores tenían un promedio de cincuenta reuniones al año. Si se considera que el reglamento de 1828 establecía dos sesiones por semana y que los períodos ordinarios se daban de febrero a abril y de agosto a octubre, calculando un promedio de 26 semanas, el número hipotético de sesiones durante los dos períodos ordinarios de un año hubiera sido de 52, con lo cual la cantidad de sesiones no resulta tan ínfima. ${ }^{46}$

Por el contrario, la productividad -entendida en cantidad de leyes y decretososciló, notándose una gran producción en 1852 , con 31 leyes $^{47}$ y 10 decretos, y una

46. Es necesario comparar con otros casos provinciales para poder corroborar esta hipótesis.

47. La distinción entre leyes y decretos fue establecida en el reglamento de 1828, siendo importante la distinción 
Tabla y gráfico No 1 . Número de sesiones, leyes y decretos divididos por temas ${ }^{1}$

\begin{tabular}{|c|c|c|c|c|c|c|c|c|c|c|c|c|c|c|c|c|}
\hline \multirow[b]{2}{*}{ Año } & \multirow{2}{*}{$\begin{array}{c}\text { Número } \\
\text { de sesiones }\end{array}$} & \multicolumn{3}{|c|}{ Elecciones } & \multicolumn{3}{|c|}{ Finanzas } & \multicolumn{3}{|c|}{ Peticiones } & \multicolumn{3}{|c|}{ Otros } & \multicolumn{3}{|c|}{ Total } \\
\hline & & $\begin{array}{c}\text { Leyes } \\
\text { (L) }\end{array}$ & $\begin{array}{l}\text { Decretos } \\
\text { (D) }\end{array}$ & $\begin{array}{l}\text { Total } \\
(\mathrm{T})\end{array}$ & $\mathrm{L}$ & D & $\mathrm{T}$ & $\mathrm{L}$ & D & $\mathrm{T}$ & $\mathrm{L}$ & $\mathrm{D}$ & $\mathrm{T}$ & $\mathrm{L}$ & $\mathrm{D}$ & $\mathrm{T}$ \\
\hline 1852 & 75 & 5 & - & 5 & 8 & $\overline{1}$ & 9 & - & 3 & 3 & 18 & 6 & 24 & 31 & 10 & 41 \\
\hline 1853 & 62 & 5 & 2 & 7 & 2 & 1 & 3 & - & 6 & 6 & 6 & 3 & 9 & 13 & 12 & 25 \\
\hline 1854 & 47 & 10 & 1 & 11 & 4 & - & 4 & - & 5 & 5 & 4 & 2 & 6 & 18 & 8 & 26 \\
\hline 1855 & 51 & 3 & - & 3 & 7 & 1 & 8 & - & 2 & 2 & - & 2 & 2 & 10 & 5 & 15 \\
\hline 1856 & 62 & 12 & 2 & 14 & 3 & 3 & 6 & - & 2 & 2 & 1 & - & 1 & 15 & 7 & 22 \\
\hline 1857 & 61 & 2 & 1 & 3 & 4 & 4 & 8 & - & 3 & 3 & 3 & - & 3 & 9 & 8 & 17 \\
\hline 1858 & 69 & 4 & 2 & 6 & 2 & 2 & 4 & - & - & - & 1 & 2 & 3 & 7 & 6 & 13 \\
\hline 1859 & $34^{2}$ & 6 & 4 & 10 & 2 & 1 & 3 & 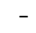 & 3 & 3 & 7 & 3 & 10 & 15 & 10 & 25 \\
\hline 1860 & Sin datos & - & 2 & 2 & 2 & - & 2 & 2 & - & 2 & 8 & 2 & 10 & 12 & 4 & 16 \\
\hline 1861 & Sin datos & 3 & 2 & 5 & 1 & 1 & 2 & 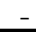 & - & - & 3 & 3 & 6 & 7 & 6 & 13 \\
\hline
\end{tabular}

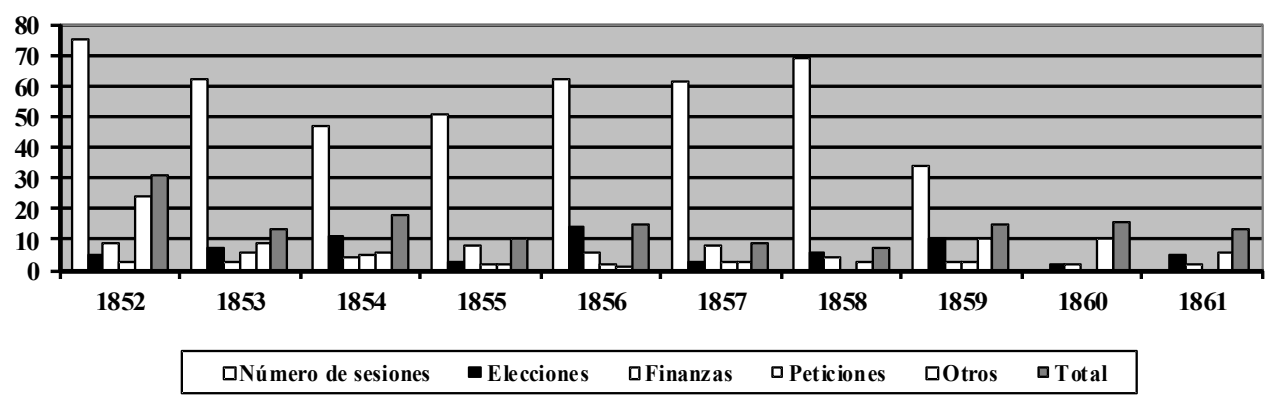

1. Todas las tablas y gráficos han sido elaborados con datos extraídos del Libro de Actas de la Legislatura, ALM, 1852-1859, T. V y VI; del Registro Oficial de la Provincia de Mendoza que comprende los años 1860, 1861, 1862, 1863 i 1864, Imprenta Pablo E. Coni, Buenos Aires, 1877 y de las carpetas 202, 203 y 204, Registro Oficial (en adelante ROPM) correspondiente a 1852-1864 de la sección gobierno (en adelante gob.), época independiente del Archivo General de la Provincia de Mendoza (en adelante AGPM).

2. Hasta el 5 de agosto.

disminución en los años siguientes, para tener un promedio de unas 15 normas y 8 decretos por año, como se ve en la tabla 1.

ya que la constitución establecía como requisito para el tratamiento de toda ley su lectura en tres sesiones diferentes, así un asunto podía ser demorado según la forma de presentarlo.
Respecto de los temas tratados en la legislación, predominaron las elecciones y las finanzas fiscales: presupuesto e impuestos. En la categoría "otros" se agruparon las sanciones sobre irrigación y defensa aluvional, organización interna 
Tabla y gráfico No 2. Análisis de las sesiones por temas

\begin{tabular}{lcccccccc}
\hline & \multicolumn{7}{c}{ Temas tratados por sesiones } \\
\cline { 2 - 9 } Año & Elecciones & Finanzas & $\begin{array}{c}\text { Orden } \\
\text { institucional }\end{array}$ & Irrigación & $\begin{array}{c}\text { Relación } \\
\text { con poderes } \\
\text { provinciales }\end{array}$ & $\begin{array}{c}\text { Relación con } \\
\text { autoridades } \\
\text { federales }\end{array}$ & $\begin{array}{c}\text { Funcionamiento } \\
\text { interno }\end{array}$ & Otros \\
\hline 1852 & 9 & 19 & 16 & 3 & 15 & 15 & 29 & 7 \\
1853 & 5 & 23 & 19 & 3 & 8 & 10 & 12 & 20 \\
1854 & 12 & 10 & 19 & - & 6 & 3 & 13 & 10 \\
1855 & 6 & 32 & 3 & 1 & 2 & - & 12 & 5 \\
1856 & 20 & 32 & - & 5 & 9 & - & 14 & 8 \\
1857 & 8 & 23 & 6 & 1 & 6 & - & 14 & 11 \\
1858 & 11 & 21 & 15 & 2 & 13 & 1 & 22 & 3 \\
1859 & 7 & 2 & 8 & - & 14 & 5 & 10 & 9 \\
Total & 78 & 162 & 76 & 15 & 73 & 34 & 126 & 73 \\
\hline
\end{tabular}

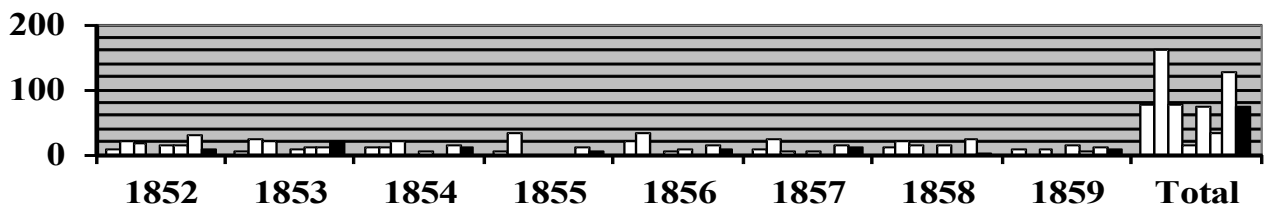

\begin{tabular}{|l|}
\hline$\square$ Elecciones \\
$\square$ Finanzas \\
$\square$ Orden institucional \\
$\square$ Irrigación \\
$\square$ Relación con los poderes provinciales \\
$\square$ Relación con las autoridad es federales \\
$\square$ Funcionamiento interno \\
$\square$ Otros \\
\hline
\end{tabular}

del estado -reformas judiciales, consejo de gobierno, atribuciones de diversos funcionarios-, ordenamiento territorial del estado -fundación de departamentos y villas-, reglamentación de la vida común y profesional -protomedicato y ejercicio de la medicina, reglamento de escribanos y notarios-. Otra fuente de normas fueron las peticiones, que incluían desde solicitudes de indulto y/o gracia de reos hasta pedidos de pensiones, sueldos o compensaciones por injusticias sufridas.
La tabla 2 muestra que solían tratarse varios temas por sesión. Lo financiero, lo electoral (convocatoria, nombramiento de autoridades, validación) y lo referido al funcionamiento interno de la sala (autoridades y comisiones, procedimientos, recepción y disciplinamiento de los integrantes) fueron los temas de mayor incidencia en las sesiones. La cámara también atendió asuntos vinculados a las autoridades nacionales, lo que era lógico en un momento donde las relaciones entre la Confederación 
y Buenos Aires eran tensas y las atribuciones correspondientes a la jurisdicción nacional y a las provinciales se hallaban en definición. ${ }^{48}$ Tampoco puede obviarse la atención que la legislatura dispensó a la relación con el poder judicial y el ejecutivo, dado que ésta se vio alterada por conflictos entre ellos. Uno de los factores que ayudaría a explicar la mayor presencia de lo financiero sería el carácter anual de las leyes de presupuesto, de impuestos

48. LANTERI, Ana Laura, De lo ideal..., Op. Cit. y de rendición de cuentas tanto como la penuria de las arcas provinciales y el déficit. El rubro siguiente fue el electoral debido a la alta frecuencia de los comicios.

El análisis cuantitativo no refleja necesariamente la importancia de un área para los legisladores. Así, el sistema de irrigación estuvo presente mediante proyectos y leyes para realizar o reparar canales y acequias y en la designación de jueces del ramo. Lo mismo ocurría con la reparación de canales

Tabla y gráfico No 3 . Análisis del origen de los proyectos de ley y decreto

\begin{tabular}{lllll}
\hline Año & $\begin{array}{l}\text { Ejecutivo } \\
\text { provincial }\end{array}$ & Legislativo & $\begin{array}{l}\text { Ejecutivo } \\
\text { nacional }\end{array}$ & Otros \\
\hline 1852 & 16 & 13 & 7 & 5 \\
1853 & 5 & 7 & 6 & 3 \\
1854 & 8 & 9 & 4 & 4 \\
1855 & 6 & 3 & 3 & 3 \\
1856 & 9 & 14 & 1 & 1 \\
1857 & 6 & 3 & 4 & 4 \\
1858 & 10 & 3 & - & - \\
1859 & 8 & 12 & 2 & 2 \\
\hline
\end{tabular}

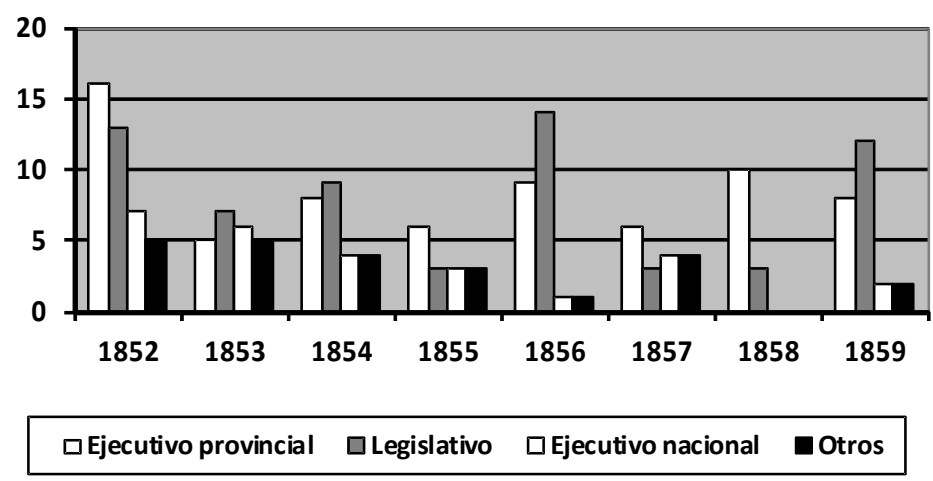


para prevenir los daños causados por las crecidas aluvionales. La organización de la justicia también fue crucial, con proyectos que buscaban organización y severidad a fin de combatir la "desmoralización".

Otra variable de análisis es el origen de los proyectos sancionados. ${ }^{49}$ Los pedidos de particulares y las iniciativas devenidas del gobierno federal requerían la mediación del ejecutivo provincial. Éste debía, además, presentar cada año las leyes de impuestos, presupuesto y rendición de gastos por disposición constitucional. Por su parte, la sala debía validar los comicios de sus integrantes, de electores de gobernador y de diputados nacionales. Así, los dos rubros de mayor incidencia ya estaban asignados por la constitución. Hay, empero, relativa simetría entre la legislación originada por la sala y el ejecutivo provincial, con menor presencia del ejecutivo nacional y de las solicitudes.

En síntesis, el análisis de las sesiones muestra que los diputados mantenían cierta asiduidad en el cumplimiento de su función -en un momento donde las sesiones se realizaban al término de la jornada porque los cargos no eran rentados-. Sin embargo, tras un prolífico 1852, la productividad de la sala disminuyó. Por el lado de las iniciativas, hay relativa paridad entre los poderes ejecutivo y legislativo.

49. Resulta difícil determinar el origen de la legislación, dada cierta vaguedad de las actas, ya que en ocasiones aparecen proyectos en la orden del día que no habían sido mencionados en su ingreso ni en su pase a comisión. También es complejo establecer si el ejecutivo se limitaba a acompañar la petición de un particular o la apoyaba. De ahí la opción de diferenciar entre los proyectos presentados por el ejecutivo provincial, por la legislatura y aquellos promovidos por el ejecutivo nacional, agrupando en "otros" los proyectos emanados de peticiones y los de origen incierto.

\section{La sala frente a las elecciones $(1852-1859)^{50}$}

Como consta en la tabla 4, se celebraron 19 comicios en el período 1852-1859; la mayoría de diputados provinciales; de nacionales (cada dos años) y de electores de gobernador (cada tres años). En cambio, los comicios para convencionales nacionales y provinciales sólo se realizaron una vez. Las cifras indican que, en general, las elecciones eran aprobadas sin discusión, aunque la existencia de debates indicaría que el consenso de otras ocasiones debía alcanzarse en el seno de la cámara y no en una instancia previa. Ninguno de los comicios para electores de gobernador fue cuestionado, mientras que las elecciones de legisladores locales y nacionales fueron impugnadas. Los motivos para impugnar una elección podían provenir de baja participación ciudadana, ${ }^{51}$ de demoras para remitir los escrutinios, de protestas de ciudadanos, ${ }^{52} \mathrm{o}$ de irregularidades $^{53}$ (la apertura de las mesas, el registro cívico, la injerencia de autoridades). ${ }^{54}$

Sólo dos comicios fueron anulados en el

50. El recorte cronológico está dado por la disponibilidad de las actas hasta 1859, ya que el tratamiento de las elecciones no se puede observar en fuentes complementarias como el ROPM.

51. Serían aprobadas porque prevaleció el parecer de que no era "causal bastante". ALM, Sesiones del 27 de junio de 1854 y del 2 de julio de 1854, Libro de Actas de la Legislatura, 1852-1854, T. V.

52. ALM, Sesiones del 9 y 12 de febrero de 1858, Libro de Actas de la Legislatura, 1854-1859, T. VI.

53. ALM, Sesión del 19 de enero de 1855, Libro de Actas de la Legislatura, 1854-1859, T. VI.

54. ALM, Sesión del 21 y 24 de diciembre de 1855; 3 y 18 de enero de 1856, Libro de Actas de la Legislatura, 1854-1859, T. VI. 


\section{Tabla No 4. Análisis del tratamiento de las elecciones por la sala}

\begin{tabular}{|c|c|c|c|c|}
\hline \multirow{3}{*}{ Tipo } & \multicolumn{3}{|c|}{ Dictamen } & \multirow{3}{*}{ Total } \\
\hline & \multirow{2}{*}{ Aprobadas sin discusión ${ }^{3}$} & \multicolumn{2}{|c|}{ Objetadas } & \\
\hline & & Aprobadas & Anuladas & \\
\hline Diputados provinciales & 6 & 2 & 1 & 9 \\
\hline Convencionales provinciales & - & 1 & . & 1 \\
\hline Electores de Gobernador & 3 & - & 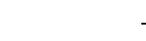 & 3 \\
\hline Convencionales nacionales & 1 & - & 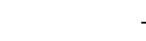 & 1 \\
\hline Diputados nacionales & $3^{4}$ & 1 & 1 & 5 \\
\hline Total & 13 & 4 & 2 & 19 \\
\hline
\end{tabular}

3. El dictamen de la Comisión de Legislación era aceptado sin objeciones, en general en una sesión.

4. La elección del 21 de mayo de 1854 fue aprobada tras una nota del poder ejecutivo provincial recomendando tal decisión por considerar las "irregularidades" como menores. Ver ALM, Sesiones del 25 de mayo y 6 de junio de 1854, Libro de Actas de la Legislatura 1852-1854, T. V.

período: las elecciones de 25 representantes provinciales y 5 suplentes que debían conformar la "primera cámara legislativa constitucional" del 9 de diciembre de 1855 y la elección de un diputado nacional titular y otro suplente del 1 de enero de 1856. En el primer caso, pese a que el dictamen de la comisión de legislación aconsejaba su aprobación, un diputado se opuso debido a los abusos del subdelegado de San Rafael, ${ }^{55}$ lo que fue confirmado por el informe solicitado al poder ejecutivo. ${ }^{56}$ Finalmente, estas elecciones fueron anuladas ${ }^{57}$ y se convocaron otros comicios ${ }^{58}$ que

55. ALM, Sesión del 21 de diciembre de 1855, Libro de Actas de la Legislatura, 1854-1859, T. VI.

56. ALM, Sesión del 3 de enero de 1856, Libro de Actas de la Legislatura, 1854-1859, T. VI.

57. ALM, Sesión del 18 de enero de 1856, Libro de Actas de la Legislatura, 1854-1859, T. VI.

58. ALM, Sesión del 22 de enero de 1856, Libro de Actas de la Legislatura, 1854-1859, T. VI. serían aprobados el 29 de febrero. ${ }^{59}$ En medio de este debate, se dio otra discusión respecto de las elecciones del 1 de enero para designar a los representantes al congreso. El problema fue que las mismas no se realizaron en el departamento de Ciudad por falta de boletas de calificación. El poder ejecutivo consultó a la sala ya que las elecciones de la campaña se habían efectuado, por lo que quería saber si se aceptaban estos comicios o se repetían. ${ }^{60}$ Los diputados supeditaron su decisión al conocimiento de los resultados, ${ }^{61}$ tras lo cual anularon las elecciones y convocaron otras. ${ }^{62}$

59. ALM, Sesión del 29 de febrero de 1856, Libro de Actas de la Legislatura, 1854-1859, T. VI.

60. ALM, Sesión del 3 de enero de 1856, Libro de Actas de la Legislatura, 1854-1859, T. VI.

61. ALM, Sesión del 8 de enero de 1856, Libro de Actas de la Legislatura, 1854-1859, T. VI.

62. Sesiones del 15 y 16 de enero de 1856, ALM, Libro de Actas de la Legislatura, 1854-1859, T. VI. Se 
Sin acceso a los escrutinios, sólo es posible suponer que el resultado de los distritos rurales no fue el deseado y optaron por otra elección.

La misma actitud especulativa se vio en otras elecciones de diputados al Congreso, esta vez de 1858, cuando la designación de Joaquín Ramírez fue anulada. Con el aditivo de una protesta contra los comicios celebrados el $17 \mathrm{de}$ enero y de una contraprotesta abogando por su validez, la sala aprobó todas las designaciones excepto la mencionada, aduciendo que "no hera persona conosida". Aunque los legisladores optaron por prorrogar el cargo de Juan Palma como diputado nacional suplente, ${ }^{63}$ una nota del ejecutivo indicaría que tal procedimiento era ilegal, ${ }^{64}$ por lo que debieron aprobar la elección. ${ }^{65}$

De este modo, si la mayoría de las elecciones fueron aprobadas -lo que señalaría que se llegaba a tal instancia con candidatos consensuados- en ciertos casos hubo debates que evidencian la existencia de fracciones en el interior de la élite y en la misma cámara, lo que fue un rasgo particular de esta década. Martínez ${ }^{66}$ trata de explicar la conflictividad de

llegó a proponer, para evitar más demoras, que "se convirtiese la Honorable Representacion en cuerpo electoral y berificase la elección de los Diputados al Congreso Nacional tomando por norte la ley adicional al reglamento de elecciones" pero se impuso el criterio de no "contrariar á los Ciudadanos comprendidos en el departamento de la Capital al libre gose de sus derechos á votar”.

63. ALM, Sesión del 9 de febrero de 1858, Libro de Actas de la Legislatura, 1854-1859, T. VI.

64. ALM, Sesión del 19 de marzo de 1858, Libro de Actas de la Legislatura, 1854-1859, T. VI.

65. ALM, Sesión del 28 de abril de 1858, Libro de Actas de la Legislatura, 1854-1859, T. VI.

66. MARTÍNEZ, Pedro Santos, Mendoza..., Op. Cit. la política mendocina como un enfrentamiento entre los federales y los liberales, unitarios o porteñistas; pero se considera que la misma imprecisión de la etiqueta para designar a los "opositores" muestra la labilidad de tales identidades políticas. Así, sin negar la importancia de la filiación ideológica, ${ }^{67}$ preferimos pensar en fracciones que se (re) alineaban de acuerdo a la coyuntura. ${ }^{68}$

\section{"El poder más alto": vicisitudes de la sala en la dinámica institucional}

Las atribuciones de la legislatura otorgaban al cuerpo legislador dispositivos para intervenir en la escena política de la provincia, los cuales serían utilizados en forma creciente a medida que la década avanzara, para hacer efectiva su autorrepresentación como el "primer poder constituido del pais". ${ }^{69}$

Así, en 1852 la cámara sometió a juicio de residencia por mal manejo de fondos

67.En un trabajo sobre los partidos políticos entre 1852 y 1880, Míguez asevera para la etapa de la Confederación que el enfrentamiento federales-unitarios respondió más a una estrategia de las élites porteñas para identificar un enemigo claro -visto como heredero de Rosas- en su lucha por la hegemonía en el estado nacional, que a un enfrentamiento ideológico. MÍGUEZ, Eduardo, "Política y partidos en la organización nacional”, en LANTERI, Ana Laura (coordinadora) Actores e identidades en la construcción del estado nacional (Argentina, siglo XIX), Teseo, Buenos Aires, 2013, pp. 171-210.

68. Debido a la centralidad de las agrupaciones políticas en el marco de la politización abierta tras el rosismo, se prefiere dejar para instancias posteriores de la investigación la profundización en él, además de considerar que el relevamiento de fuentes alcanzado no permite adelantar un análisis más preciso.

69. La expresión aparece varias veces, sobre todo en momentos álgidos de disputa con los otros poderes. 
públicos $^{70}$ al ex gobernador Alejo Mallea, que había renunciado a principios de ese año, hallándolo culpable. ${ }^{71} \mathrm{Si}$ bien es imposible desconocer el ambiente adverso a los funcionarios más vinculados a Rosas, en Mendoza los elencos casi no cambiaron tras la adhesión de la provincia al levantamiento de Urquiza. ${ }^{72}$ De igual modo, en 1853 , la sala dio lugar a la petición de un ciudadano que había protestado lo que consideraba una injerencia indebida del poder ejecutivo en un proceso judicial, anulando los decretos de éste. ${ }^{73} \mathrm{La}$ misma postura adoptaría la sala ante una queja similar, aunque la nota también expresaría que su decisión no implicaba "juzgamiento". ${ }^{74}$

Apenas iniciada la década, la legislatura mostraba su autonomía e independencia en su falta de reparos para someter a un ex gobernador a juicio de residencia y conceder las peticiones de ciudadanos si consideraba que el ejecutivo se había excedido en sus funciones, usurpando atribuciones correspondientes a otro poder.

En otras ocasiones, la cámara de representantes se mostró condescendiente, prefiriendo el proyecto de presupuesto

70. ALM, Sesiones del 15 de junio, 3, 10, 13 y 17 de agosto; del 9, 11, 15,18, 20, 22, 23 y 24 de diciembre de 1852, Libro de Actas de la Legislatura, 1852-1854, T. V.

71. ALM, Sesión del 28 de diciembre de 1852, Libro de Actas de la Legislatura, 1852-1854, T. V.

72. MARTÍNEZ, Pedro Santos, Mendoza..., Op. Cit., pp. 26-32.

73. ALM, Sesión del 14 de enero de 1853, Libro de Actas de la Legislatura, 1852-1854, T. V.

74.ALM, Sesión del 18 de mayo de 1857, Libro de Actas de la Legislatura, 1854-1859, T. VI; 19 de mayo de 1857, doc. 77, carp. 756, gob., AGPM y de diciembre de 1858, exp. 1182, carp. 29 ALM.

34 presentado por el ejecutivo a otro más reducido que había redactado la comisión de Hacienda. ${ }^{75}$ La sala también retrocedió en casos en que creía que ciertas actitudes podrían haber irritado al ejecutivo, por lo que un diputado sostuvo que "se hacia impelente la necesidad... [de] que ambos poderes ... guardasen la mejor armonia y buena intelijencia en la espedicion de sus atribuciones". ${ }^{76}$

Una diferencia más seria surgió en 1854 cuando el diputado y juez del crimen Juan Palma, envió una nota a la sala desde la cárcel, pidiendo que se arbitrara no sólo su salida, sino una declaración de la inmunidad de los representantes que adujo "necesaria para... asegurar la independencia y libertad, sin cuyas condiciones los DD. del Pueblo no podian llenar la noble mision de que son encargados". ${ }^{77} \mathrm{La}$ cámara consideró grave el asunto y citó al ministro de gobierno para que diera explicaciones. Aunque el único resultado fue la presentación de un proyecto de ley de inmunidad ${ }^{78}$ que no sería tratado. El caso ilustra la reacción de la sala ante lo que consideró un ataque a su dignidad.

Por otra parte, la legislatura demoraba tanto el tratamiento de algunas leyes que causaba la reacción del ejecutivo. Así ocurrió en 1855, cuando el gobernador Segura presentó su renuncia ya que, al carecer de una ley de impuestos adecuada, el estado adolecía de recursos. La sala rechazó su dimisión,

75.ALM, Sesión del 5 de mayo de 1853, Libro de Actas de la Legislatura, 1852-1854, T. V.

76. ALM, Sesión del 12 de septiembre de 1853, Libro de Actas de la Legislatura, 1852-1854, T. V.

77. ALM, 11 de abril de 1854, exp. 959, carp. 25.

78. Presentado el 9 de mayo de 1853, ALM, Libro de Actas de la Legislatura, 1852-1854, T. V. 
prometiendo ocuparse del asunto. $^{79}$ De igual modo, en 1858 el gobernador Moyano renunció. La cámara denegó su presentación, alegando que debía dar el ejemplo en el cumplimiento del deber. ${ }^{80}$

Aun cuando la cámara tratara las leyes presentadas por el ejecutivo, no siempre lo hacía de acuerdo con las metas de éste. En 1856, el gobernador objetó algunos términos de la ley de presupuesto ${ }^{81}$ frente a lo cual la sala respondió que "no encuentra razon alguna que haga precisa una reforma... ni una revisacion de la ley de impuestos". ${ }^{82}$

Por otra parte, la sala era consultada por la cámara de justicia -instancia superior del poder judicial-, respecto de la pervivencia de instituciones como el tribunal de nulidad e injusticia notoria tras la sanción de la constitución nacional. ${ }^{83}$ La cámara trató,

79. ALM, 27 de febrero de 1855, exp. 1008, carp. 26.

Como se ha señalado, la penuria fiscal era endémica, de lo que dan cuenta numerosos proyectos de ley presentados y los mensajes de los gobernadores. Ver, por ejemplo ALM, 9 de marzo de 1855, exp. 1011, carp. 26; 2 de febrero de 1859, exp. 1188, carp. 3; 11 de febrero de 1860, exp. 1284, carp. 31; 3 de febrero de 1861, exp. 1339, carpeta 31.

80.12 de mayo de 1858 , doc. 76 , carp. 756a, poderes, AGPM; 11 de mayo de 1858, exp. 1163, carp. 29, ALM.

81. ALM, Sesión del 19 de mayo de 1856, Libro de Actas de la Legislatura, 1854-1859, T. VI.

82. AGPM, 20 de junio de 1856, doc. 36, carp. 756a, gob., y ALM, sesión del 20 de junio de 1856, de Actas de la Legislatura, 1854-1859, T. VI.

83. ALM, Sesiones del 16 de marzo y 28 de abril de 1858, Libro de Actas de la Legislatura, 1854-1859, T. VI.

Esto, como se ha visto, dio lugar a cuestionamientos respecto de la incumbencia de una sala provincial para examinar la aplicación de la constitución nacional. $E$. C., Mendoza, 17/11/1857. además, de mediar $^{84}$ en el conflicto entre el gobernador Moyano y la cámara de justicia referente al nombramiento de los jueces suplentes,${ }^{85}$ práctica habitual por las constantes recusaciones e implicancias en un poder judicial con una élite pequeña de donde extraer sus magistrados. ${ }^{86}$

Sin embargo, la primera ruptura abierta se dio recién en 1859, cuando la decisión de la sala de dar por finalizado el mandato del gobernador el 25 de febrero, condujo a la disolución de ésta por parte de Moyano -que se apresuró a llamar a elecciones para constituir una representación más dócil-. El conflicto incluyó la elección de Federico Maza como gobernador -ante el deceso del titular-, una sublevación en el este provincial y una intervención federal.

Una situación similar se presentaría al año siguiente cuando las ácidas críticas de El Constitucional contra la legislatura ${ }^{87}$ a la

84. ALM, Sesiones del 16, 20, 26, 27 y 30 de julio de 1858, Libro de Actas de la Legislatura, 1854-1859, T. VI.

85. El conflicto se inició en marzo de 1858 y aparentemente, la resolución no se dio hasta 1860, ya que sólo entonces el gobernador Nazar refirió a la solución del conflicto. AGPM, Sección Judicial, (11 de febrero de 1860, exp. 1284, carp. 31). Exp. 1149, 1151, 1153, 1154, 1156, 1557, 1161, 1166 y 1170; carp. 29, ALM y doc. 26, carp. 418.

86. Se ha empezado a indagar en el fenómeno en GARCÍA GARINO, Gabriela, “Honor...”, Op. Cit. Para Buenos Aires consultar CORVA, María Angélica, "Íntegros y competentes'. Los magistrados de la provincia de Buenos Aires en la segunda mitad del siglo XIX", en BARRIERA, Darío (compilador) Justicias y fronteras. Estudio sobre historia de la justicia en el Rio de la Plata. Siglos XVI-XIX, Editum, Murcia, 2009, pp. 179-204.

87. Una situación similar se dio en 1858, cuando los diputados solicitaron la acción del ejecutivo ante los "insultos" del diario Constitución. Sin embargo, las fuentes no muestran que el asunto haya trascendido. Ver 
que calificó de "chingana", hicieron que la sala "intimara" al ejecutivo a procesar a los culpables o, al menos, a rescindir el contrato con los editores, dejando de sesionar hasta entonces. Tras un intercambio de notas cada vez más duras, el ejecutivo decidió disolver la sala, amparándose en el vencimiento del mandato de la mitad de los representantes, y convocando a los que debían completarlo junto a los electos en febrero de aquel año. ${ }^{88}$

Ambas disputas planteaban como problema la posición de un poder respecto del otro. Los resultados difirieron: en 1859, la primera medida de Pascual Echagüe como interventor fue rehabilitar a la sala depuesta, la que anuló las medidas de la electa en marzo. ${ }^{89}$ Por el contrario, si bien Nazar suspendió en 1860 su decreto de disolución de la sala a instancias del gobierno nacional, ${ }^{90}$ de todas formas se sustituyó a los diputados y se reanudaron las sesiones sin que se modificara la redacción del diario provincial. ${ }^{91}$

No puede obviarse la intervención del poder federal. En 1859 el enfrentamiento condujo a la sublevación de varios comandantes de guardia nacional del este provincial y a la

sesión del 11 de mayo de 1858, ALM, Libro de Actas de la Legislatura, 1854-1859, T. VI y 11 de mayo de 1858, exp. 1163, carp. 29; AGPM, Sección Gob., 12 de mayo de 1858 , doc. 76, carp. 756 . No se han encontrado ejemplares de aquel diario en los archivos consultados.

88. Para ver una minuciosa narración de ambos sucesos consultar MARTÍNEZ, Pedro Santos, Mendoza ..., Op. Cit., pp, 135-137; 149-154; 173-180.

89. AGPM, Sección Gob.,Abril de 1860, doc. 26, carp. 203.

90.ALM, 22 de abril de 1860, exp. 1299, carp.31.

91. AGPM, 23 de abril de 1860, doc. 28 y 23 de abril de 1860 , doc. 29 , carp. $756 \mathrm{~b}$, poderes. intervención federal ${ }^{92}$-la única en Mendoza en el período estudiado-. De esta manera, se observó en esta provincia lo que fue más habitual para otras como San Juan, Tucumán y Corrientes: ${ }^{93}$ la apelación a las armas para resolver un conflicto político-institucional y la intervención del gobierno federal para zanjar la situación. Por el contrario, las diferencias de 1860 no llevaron a las armas y fue suficiente la intercesión epistolar del gobierno nacional para resolver un conflicto según el parecer del primer mandatario.

Sin embargo, ambos enfrentamientos muestran que la sala había construido su imagen como "el más alto poder provincial", al punto que le comunicó al gobernador:

ha sancionado que por cuanto ha espirado el dia 21 del corriente el periodo administrativo de V. E., el ejercicio del poder ejecutivo de la provincia reside en el presidente de la H. Camara, y aprocedido á la eleccion de un Gobernador interino. ${ }^{94}$

agradeciéndole escuetamente sus servicios.

92. Fue justamente la llegada de Pascual Echagüe lo que evitó el enfrentamiento armado entre las fuerzas sublevadas de Nazar y del recientemente electo gobernador Federico Maza.

93. Para San Juan: LANTERI, Ana Laura, "Provincias y poder central en la 'Confederación'. Una aproximación a la vida política de San Juan a partir de la Circunscripción Militar del Oeste (1855/9-1858)", en XIV Jornadas Interescuelas/departamentos de Historia, Facultad de Filosofía y Letras, Universidad Nacional de Cuyo, Mendoza, 2013, mimeo; para Tucumán NAVAJAS, María José, Actores..., Op. Cit., pp. 33-86 y para Corrientes, BUCHBINDER, Pablo, Caudillos..., Op. Cit. pp. 73-106.

94. ALM, Sesión del 25 de febrero de 1859, Libro de Actas de la Legislatura, 1854-1859, T. VI; ALM, 25 de febrero de 1859, exp. 1190, carp. 30; AGPM, doc. 92, carp. 756a, poderes. 
Moyano, por su parte, no dudó en disolver por decreto la sala, ${ }^{95}$ fundado en su visión sobre aquella sesión:

La... Cámara arrojó la anarquia en medio de la provincia, proclama sin embozo el desconocimiento de la autoridad lejítima, alza en alto la arbitrariedad y se coloca á la cabeza de una rebelion que amenaza trastornar el órden y ensangrentar al pais. ${ }^{96}$

Un año después, las representaciones de los actores no habían cambiado. Así, la legislatura

exije imperiosamente de V. E. proceda en el acto a demandar la reparacion condigna por el órgano y medios que las leyes ponen a su alcance ... haciendo a V. E. responsable de las consecuencias que sobrevinieran de la omision de este paso". ${ }^{97}$

El reclamo de la sala se asentaba en un discurso en el cual ella era la fuente de autoridad y legitimidad de los demás poderes del estado, en tanto cuerpo que condensaba la soberanía popular:

la Cámara Lejislativa, segun las elevadas atribuciones que le confiere la Constitucion,

95. ALM, 15 de marzo de 1859, exp. 1202, carp. 30.

96. ALM, 15 de marzo de 1859, exp. 1202, carp. 30. E1 parecer de Moyano sobre "el anticonstitucional i sedicioso procedimiento de la Lejislatura de 1858 en la sesión del 25 de Febrero" sería confirmado por la nueva legislatura, reunida en su sesión del 16 de marzo. ALM, Libro de Actas de la Legislatura, 1854-1859, T. VI.

97. ALM, 17 de marzo de 1860, exp. 1293, carp. 31. como el Cuerpo de quien emanan los mandatos que deben cumplir i hacer cumplir los demas poderes del Estado, como la encarnacion de la soberania de la Provincia, como la representacion legal de la voluntad del Pueblo y en una palabra, como el Cuerpo mas sagrado y respetable que regla la autoridad de todos los poderes, incluso el que V. E. desempeña, la Cámara Lejislativa es el mas alto poder de la Provincia y el primero colocado en el orden constitucional. $^{98}$

Pero el esquema institucional del gobernador se oponía a aquel, postulando la independencia e igualdad entre los poderes, rehusando acceder a lo que consideraba exigencias indebidas de una sala que estaba incurriendo en actos inconstitucionales y, aun, sediciosos. Nazar negó toda pretensión a vindicar a la sala "puesto que ningun art. ${ }^{\circ}$ constitucional me hace el ajente de su honra”, agregando:

[D]esconozco la autoridad con que pueda atreverse la Camara Legislativa a intimar alguna de sus resoluciones.... Por la Carta Fundamental de la Confederacion i por la Constitucion orgánica de la Provincia, el Ejecutivo es un poder tan independiente como la Honorable C. Lejislativa. ${ }^{99}$

De esta manera, el corazón de la disputa yacía en concepciones encontradas del vínculo entre los poderes: superioridad del legislativo, contra la postulación de su igualdad e independencia por parte del ejecutivo. ${ }^{100}$

98. ALM, 22 de marzo de 1860, exp. 1295, carp. 31.

99.Ibídem.

100. Este último punto fue advertido por un lector que expresó que diputados "han sostenido $[. .$.$] que el$ 
El último año del período recortado no mostró episodios de esta competencia, pero sí la independencia de la sala al negarse a modificar su parecer sobre el lugar de la residencia de las autoridades tras el terremoto que asoló Mendoza el 20 de marzo de 1861. ${ }^{101}$

\section{A modo de conclusión}

En las páginas precedentes se ensayó un análisis de la legislatura entre 1852 y 1861, partiendo de la hipótesis de que altas expectativas sobre el carácter transformador de la constitución y de la legislación emanada de la sala provincial dieron lugar a un discurso negativo respecto de su accionar. Sin embargo, el seguimiento de la praxis legislativa mostró que ésta no se correspondía con aquella representación.

Así, una consulta de El Constitucional corroboró la existencia de dos miradas opuestas: por un lado, la conceptualización de la cámara como fuente de legislación que modificaría rápidamente una realidad percibida como problemática; por el otro, el desencantamiento respecto de la prensa por la resistencia de la realidad a los cambios y la inercia del tejido social, que llevaba a responsabilizar a la cámara por la falta de efectividad de las leyes y aún de las mismas constituciones nacional y provincial. Por otro lado, se argumentó que este tipo de imágenes no pueden ser escindidas del rol del periódico como portavoz del ejecutivo provincial.

poder de que se haya revestido la H. C. de R. es superior en soberanía á aquel con que se haya caracterizado el Supremo Poder Ejecutivo". E. C., Mendoza, 10/4/1860.

101. ALM, 9 de abril de 1861, exp. 1340 y 11 de abril de 1861, exp. 1342, carp. 32 .
A continuación, se trató indagar cuáles habían sido las prácticas desplegadas por la legislatura en el período mediante un examen cuantitativo, concluyendo que la sala se reunió de forma bastante regular y que si bien muchas de las sesiones se destinaban a discusiones que podían ser consideradas bizantinas, predominaron los temas fiscales $\mathrm{y}$ electorales en las sesiones, por lo que los representantes fueron estableciendo ciertas pautas institucionales e impositivas. Por otra parte, hubo mociones que demoraron años para su tratamiento, mientras que otras siquiera fueron consideradas.

Asimismo, se realizó un breve examen sobre la actuación de la cámara respecto de las elecciones. Como instancia que juzgaba la validez de los comicios, se ha visto que, en general, las aprobó sin discusión, y aun cuando hubo objeciones, sólo dos elecciones fueron anuladas, lo que parece haber respondido más a cálculos estratégicos que a fallas en la realización, como las fuentes muestran en la mayoría de los actos. Por otro lado, los debates respecto de la legitimidad de los comicios pueden ser vistos como síntomas de la politización abierta tras la caída de Rosas y de la existencia de fracciones entre las elites mendocinas, que no habían podido dirimir sus diferencias en instancias previas.

Finalmente, se complementó el análisis anterior con un examen de la relación de la cámara con los otros poderes, especialmente el ejecutivo, mostrando cómo aquella se fue consolidando progresivamente en su rol de interlocutor y contralor de éste. Así, los representantes exhibieron una voluntad de posicionamiento de su rol, 
autorrepresentándose como el "primer poder de la provincia" que encarnaba la soberanía del pueblo y, por lo tanto, era fuente de la autoridad de los otros poderes. Este afianzamiento se mostró tanto en la intercesión en el conflicto entre los otros dos poderes, como en las pugnas que se dieron con el ejecutivo, especialmente a finales de la década, lo cual no debió ser ajeno al proceso de fortalecimiento de la sala durante el decenio.

De este modo, el análisis realizado muestra que las imágenes negativas de la sala como un cuerpo anclado en el pasado que no cumplía con su deber, e incluso era un obstáculo para la labor del ejecutivo, no correspondían a una cámara de representantes que, pese a las limitaciones propias de un aparato estatal en construcción y de una élite exigua, desplegó un accionar que no dejó de buscar un lugar de liderazgo en la vida política provincial.<smiles>C=[Te]C</smiles>

Recibido: $20 / 11 / 2013$

Aceptado: 13/06/2014 Publicado: 31/07/2015 